\title{
CAPÍTULO 11 \\ O TRABALHO DO PSICÓLOGO NA POTENCIALIZAÇÃO DAS FUNÇÕES PSICOLÓGICAS SUPERIORES: UM ESTUDO DE CASO $^{*}$
}

\author{
Fabiola Batista Gomes Firbida \\ Marilda Gonçalves Dias Facci \\ Ana Paula Alves Vieira \\ Glaucia Rodrigues da Silva
}

\section{Introdução}

$\mathrm{Na}$ educação, muitas vezes os psicólogos são convocados a explicar e intervir nas dificuldades do processo de escolarização. Na história da Psicologia, conforme Massim (1990) e Antunes (1998) vemos que o enfrentamento das dificuldades escolares sempre foi tratado no aspecto individual, o que levou à normatização do comportamento por meio de regras de higiene impostas pela Medicina sanitarista, e à identificação do comportamento desviante, para que fosse controlado. Dessa forma, o desenvolvimento psicológico dos escolares era compreendido a partir de suas bases mais elementares, as biológicas, levando ao uso exclusivo da medicação, que cresce demasiadamente a cada dia, comprometendo mais a saúde das pessoas do que ajudando.

Desde a década de 1990 a Psicologia vem buscando pressupostos teórico-práticos para desenvolver uma intervenção que vá na contramão de ideias patologizantes e discriminatórios e que busquem compreender o desenvolvimento do psiquismo como atrelado a condições histórico-sociais, dando destaque, como elucida Leontiev (1978), a educação como fundamental para o processo de humanização dos indivíduos. Para esse autor, o desenvolvimento do psiquismo ocorre por meio da apropriação da cultura, no processo educativo. Inicialmente na vida cotidiana, na sequência com o processo de escolarização e caminhando até o ponto de o homem se tornar autodidata.

$\mathrm{Na}$ busca da superação de uma visão biologicista e individualizante, apresentamos neste artigo uma discussão sobre o desenvolvimento das funções psicológicas superiores a partir da Psicologia Histórico-Cultural, com foco na interfuncionalidade das funções pela internalização dos signos. Para tanto, apresentaremos uma experiência realizada por meio do grupo de apoio psicoeducacional com crianças do ensino fundamental. Destacaremos, mais especificamente, o trabalho realizado com um aluno.

Inicialmente, discorreremos sobre a interfuncionalidade das funções psicológicas superiores, e em sequência apresentaremos a intervenção realizada com o aluno, abordando o processo de avaliação realizado e sua participação no grupo de apoio psicoeducacional.

\section{A interfuncionalidade das funções psicologicas superiores}

Segundo Vygotski (2000), o conceito de função psicológica superior abarca dois fenômenos que não podem ser entendidos separadamente. O primeiro se refere ao "domínio dos meios externos do desenvolvimento cultural e o do pensamento", que envolve a linguagem, o desenho, a escrita e o cálculo. O outro alude às formas especiais de funções, que não seguem uma linha exata de desenvolvimento, sendo elas a atenção, a memória e a formação de conceitos, entre outros. O conjunto desses fenômenos pode ser

${ }^{*}$ DOI - 10.29388/978-65-86678-97-0-f.157-172 
classificado como "desenvolvimento das formas superiores de conduta da criança" (VYGOTSKI, 2000, p. 29). Vygotski e Luria (2007) analisam que, assim como a fala, a leitura, a escrita, o cálculo e o desenho também agem como processos simbólicos que atuam na regulação dos processos psíquicos do homem.

Em nosso estudo focaremos em como essas formas especiais de funções são potencializadas na atividade proposta no grupo de apoio psicoeducacional. A linguagem, o desenho, a escrita e o cálculo, junto com os instrumentos físicos, atuam como mediadores na superação das formas elementares de desenvolvimento. Para tanto, partiremos da premissa de que as FPS agem a partir de um sistema interfuncional, estabelecendo novas conexões com a presença dos signos (VIGOTSKI, 2000).

As funções psicológicas superiores são mediatizadas por instrumento e signos, e são essas mediações que possibilitam que os outros homens se apropriem da experiência humana acumulada historicamente. Por meio do emprego de ferramentas e da atividade de trabalho o homem desenvolveu os órgãos artificiais para substituir o desenvolvimento natural, criando signos externos que auxiliam na realização de ações mentais, como criar, perceber, abstrair, memorizar e planejar (VYGOTSKI, 2000).

Os signos e os instrumentos têm a função de mediar a constituição do psiquismo: o instrumento modifica a situação externa do objeto e o signo age na reestruturação interna psíquica, modificando a conduta do sujeito. Vygotski (2000) afirma que a apropriação do signo promove um salto qualitativo no desenvolvimento do homem, pois o liberta dos limites orgânicos, de uma relação determinista com a natureza, e estabelece uma nova relação com sua realidade, em que ambos influenciam mutuamente.

Segundo Asbahr e Nascimento (2013), as capacidades orgânicas do homem não são modificadas em novas capacidades devido a um aprimoramento natural, mas a capacidade de ver e ouvir se modificam em consequência das relações sociais do homem com seu entorno, por meio da apropriação da cultura e dos novos objetos criados por ele. Não é um processo de adaptação, mas de transformação. Para as autoras, a transformação de uma função está relacionada à modificação de outras funções, evidenciando que o desenvolvimento psicológico segue mudanças culturais e não naturais.

Almeida e Antunes (2005) analisam que à medida que as relações da criança com o mundo se complexificam, pela apropriação dos conhecimentos humanos, essas funções, antes externas, se tornaram internas. A internalização age na possibilidade de reconstruir internamente o que era uma operação externa, por isso envolve a transformação de uma operação externa em interna, de interpessoal para intrapessoal, e essas alterações se dão ao longo do desenvolvimento por operações com signos. A linguagem, como signo mediador, desempenha importante papel na internalização dos signos sociais, já que para Vygotski (2000) estabelece a intercomunicação dos signos que serão internalizados e se tornaram processos intrapsíquicos.

De acordo com Martins (2011, p. 352), Vygotski, ao tratar sobre a existência de um sistema dinâmico atuando na base das funções psíquicas superiores, entendeu que "[...] existe uma dinâmica psíquica instituída pela especificidade das mesmas e pelo papel que desempenham nas atividades realizadas pelo indivíduo ao longo de seu desenvolvimento". Segundo a autora, não é apenas uma função que muda, mas acontece sucessivos arranjos interfuncionais que leva a novas reorganizações e articulações entre as funções, gerando o movimento, e tal é provocado pelo emprego de signos. Portanto, o emprego de signos não surge espontaneamente, mas na atividade laboral do homem, isto é, no processo de transformação de sua realidade.

Vygotski e Luria (2007) alegam que operar com signos envolve um processo complexo de mudanças qualitativas que acontecem no decorrer do desenvolvimento. Por conseguinte, para Vygotski (1999), signos atuam como meio de comunicação social que se interpõe na relação entre as pessoas e que atua como um meio auxiliar na interiorização das 
funções psíquicas sociais, como a atenção voluntária, por exemplo. O que muda são as conexões entre as funções e são os signos que fazem a conexão entre elas.

Como afirma Vygotski (1999), o signo "é o próprio meio da união das funções em nós mesmos, e poderemos demonstrar que sem esse signo o cérebro e suas conexões iniciais não podem se transformar nas complexas relações, o que ocorre graças à linguagem" (VIGOTSKI, 1999, p. 114).

Os instrumentos, segundo Vygotski (2000), fazem uma reestruturação global no desenvolvimento do psiquismo e não de alguns elementos, pois as FPS se reorganizam para lidar com o desafio apresentado, provocando um salto qualitativo. De acordo com Vygotski (1999), as mudanças acontecem na estrutura interfuncional, entre os novos nexos interfuncionais, que denominou de sistema psicológico. Esses nexos são desenvolvidos pela "[...] riqueza dos vínculos da pessoa com a realidade [...]" (MARTINS, 2011, p. 59), pela relação dialética entre maturação orgânica e apropriação da experiência social, que acontece a partir da atividade de trabalho.

Os sistemas psicológicos, a forma superior de comportamento, aparecem duas vezes. Por meio de uma forma coletiva, nas atividades externas ou sociais, como funções interpsíquicas, e depois nas atividades individuais, como funções intrapsíquicas, que regulam o próprio comportamento da criança (VYGOTSKI, 2005).

De acordo com Georg (2002), o signo tem a função de estabelecer a relação do sujeito com os outros e, quando internalizados, do sujeito consigo mesmo. Portanto, as FPS surgem nas relações coletivas que movimentam as funções que estão atuando isoladamente, para se reorganizarem em novas conexões para fazerem parte do sujeito. Agora atuam como funções intrapsíquicas, na regulação do comportamento. Como alega Vygotski (2000, p. 146), o signo "[...] é sempre um meio de relação social, um meio de influência sobre os demais e tão somente depois se transforma em meio de influência sobre si mesmo".

De acordo com Vygotski e Luria (2007, p.21), o uso de instrumentos e o desenvolvimento dos signos é próprio do comportamento superior, pois o uso da atividade simbólica possibilita o surgimento de novas formas de comportamento. Portanto, o domínio dos instrumentos e a criação dos signos fez o homem libertar-se de sua condição biológica e obter domínio sobre a natureza e sobre si mesmo.

Sendo assim, a qualidade das mediações entre o adulto e a criança é de extrema importância para o desenvolvimento das FPS, pois, como elucidamos acima, tais funções existem primeiro como atividade interpsíquica para depois se tornarem intrapsíquica. É o adulto que apresenta e aplica as formas de condutas sociais na criança até que ela possa organizá-las, tendo como parâmetro o outro, e faça delas condutas próprias do seu comportamento.

Cada idade é uma etapa qualitativamente nova, que possui múltiplas mudanças e características peculiares. Dessa forma, ao passar de uma etapa a outra novas formações psíquicas surgem, formações que não existiam na fase anterior. Para compreender o desenvolvimento psíquico da criança nos diferentes períodos etários, Vygotski (1996, v.4) resgata as mudanças qualitativas que ocorrem em cada etapa da vida da criança, isto é, as qualidades internas de cada período. Segundo Pasqualini e Eidt (2016), essas mudanças qualitativas que caracterizam cada período do desenvolvimento foi explicado por Vygotski por meio dos conceitos de situação social do desenvolvimento, atividade dominante, neoformações e crise.

Para Vygotski (1996), a situação social do desenvolvimento não se refere apenas ao entorno externo a ela, mas é uma relação dinâmica entre a criança e seu meio; relação esta que é específica em cada idade. É a partir dessa relação dinâmica que a criança vai construindo novas formações em sua personalidade, na transformação do social em individual. Vygotski (1996, p. 254-255) afirma que as mudanças internas que ocorrem no 
desenvolvimento da criança, em cada período, “[...] determinam, no aspecto mais importante e fundamental, a consciência da criança, sua relação com o meio, sua vida interna e externa, todo o curso do seu desenvolvimento no período dado".

Vygotski (1996) analisa que ao conhecer a situação social do desenvolvimento, fazse importante saber a origem do desenvolvimento das novas formações psíquicas em cada período, pois a situação social não é a mesma sempre, ela se modifica e produz novos períodos de desenvolvimento. Logo, o desenvolvimento da criança não pode ser explicado pelas mudanças biológicas, mas pelas relações que são engendradas na construção de sua existência social que implica em suas mudanças internas.

Nas palavras de Vygotski (1996, p. 265), "A nova estrutura da consciência, adquirida em cada idade, significa sem dúvida que a criança percebe de maneira diferente sua vida interior, assim como o mecanismo interno de suas funções psíquicas". Dessa forma, podemos afirmar que em cada período etário o sistema de relações da criança se reestrutura, caracterizando mudanças qualitativas (internas) em seu desenvolvimento.

A estrutura da idade é um aspecto importante do desenvolvimento defendido por Vygotski (1996), que corresponde às mudanças globais internas de cada período da infância. Ainda que se processem mudanças microscóspicas da personalidade da criança, porque essas transformações se dão por dentro e não por fora, é o conjunto delas, a partir de uma relação dinâmica, que provoca uma reestruturação da personalidade da criança como um todo. Diante disso, Vygotski (1996, p. 262) afirma que "[...] em cada período etário encontramos sempre uma nova formação central como uma espécie de guia para todo o processo do desenvolvimento, que se caracteriza a reorganização de toda a personalidade da criança sobre uma base nova".

Vygotski (1996), ao questionar as teorias que explicam a periodização do desenvolvimento, afirma que a base para explicar as mudanças de idade deve ser buscada nas mudanças internas, ou seja, as novas formações, decorrentes da interação com os outros homens na apropriação da cultura. $\mathrm{O}$ autor define que as novas formações seriam

[...] o novo tipo de estrutura da personalidade e de sua atividade, as mudanças psíquicas e sociais que se produzem pela primeira vez em cada idade e determinam, o aspecto mais importante e fundamental, a consciência da criança, sua relação com o meio, sua vida interna e externa, todo o seu curso de desenvolvimento no período dado. (VYGOTSKI, 1996, p. 254-255).

Essas neoformações ocorrem em função da relação que a criança estabelece com o meio. Conforme vai se desenvolvendo, o meio vai exigindo novos comportamentos. Em uma relação dialética entre o contexto em que a criança vive e a apropriação da cultura, novas formações ocorrem no psiquismo. Dessa maneira, não é possível tratar o desenvolvimento infantil partindo de uma perspectiva estável e linear, pois a cada nova situação social a criança se reestrutura internamente, configurando assim as idades críticas, que, segundo Vygotski (1996, p. 255), são a “[...] presença de crises no desenvolvimento da criança $[\ldots . .$. ".

Essas idades críticas se caracterizam por mudanças e rupturas na estrutura da personalidade, devido às novas relações e espaços ocupados pela criança na sociedade. As crises não se apresentam apenas como manifestações externas, mas são, sobretudo, uma necessidade interna que as provoca. As idades críticas também não podem ser entendidas como períodos negativos do desenvolvimento, por mais que sejam muito característicos comportamentos contrários aos traços anteriores de seu desenvolvimento, nem tampouco são iguais para todos (VYGOTSKI, 1996).

O que acontece nas idades críticas é o aparecimento do novo, o que implica em deixar o velho, não sendo fácil nem para a criança e nem para quem está se relacionando 
com ela. Vygotski (1996) vai afirmar que por trás da manifestação negativa estão ocultas as mudanças positivas na personalidade, por isso o autor desenvolve seu conceito de periodização apresentando as idades a partir das crises.

No decorrer do desenvolvimento, segundo Leontiev (1987), a relação estabelecida com a realidade vai se modificando, o que significa dizer que alguns tipos de atividades vão ganhando espaço que não existiam anteriormente e reorganizações psíquicas vão acontecendo. Cada período do desenvolvimento é marcado por uma atividade principal, que não consiste na mais frequente, mas na que produz novas formações psicológicas (ELKONIN, 1987). Segundo Leontiev (2014a), com novos motivos surgem novas atividades. Vale a pena mencionar que esses motivos advêm de uma contradição entre o seu entorno e suas potencialidades e se relacionam com mudanças na forma como a criança atribui sentido aos fenômenos.

Assim, no período pré-escolar a criança resolve uma grande contradição na brincadeira de faz de conta: a necessidade de agir e a impossibilidade de executar as operações (LEONTIEV, 2014b). No período de transição entre esse período e o escolar, a criança já começa a se desinteressar pelo que a interessava anteriormente e novos tipos de brincadeiras passam a ocupar um novo espaço em sua vida, envolvendo conversas e a companhia de crianças mais velhas (LEONTIEV, 2014).

No caso do nosso estudo com crianças no início do ensino fundamental, a entrada na escola modifica as relações que têm com seu entorno, que exigirá delas uma nova postura, devido à posição social que adquirem como estudantes. A nova situação social influencia o conteúdo das idades críticas, portanto a idade escolar se caracteriza pela crise dos sete anos.

Segundo Vygotski (1996), nessa idade se apresenta a instabilidade na vontade e no estado de ânimo, bem como a independência e a mudança de comportamento diante de outras crianças. Vygotski (1996) afirma que a crise dos sete anos se caracteriza pela perda da espontaneidade.

No período anterior à entrada da criança na escola, no período pré-escolar, por meio do domínio consciente do jogo, de acordo com Pasqualini (2006), ocorre uma preparação para que a criança desenvolva o domínio da própria conduta, necessária para o desenvolvimento da atividade de estudo, e, por isso, a importância do educador nesse processo de controle sobre a brincadeira como uma atividade para ensinar e não apenas brincar.

Nesse sentido, Vygotski (2001) afirma que o conhecimento científico ensinado na escola, por meio da atividade de estudo, vai substituindo as relações imediatas que a criança tem com sua realidade e reorganiza suas funções psíquicas, implicando no aparecimento da tomada de consciência e da voluntariedade, que são as novas formações nessa idade.

Antes de entrar na escola, a criança já domina as formas gramaticais, mas, devido ao ensino da escrita e da gramática, Vygotski (2001, p. 320) afirma que passam "[...] a tomar consciência do que faz e a operar voluntariamente com as suas próprias habilidades". Por isso, o autor defende que o desenvolvimento da estrutura de cada idade implica na relação dinâmica entre o todo e suas partes, que implicaram no desenvolvimento de novos nexos entre as novas formações da estrutura subsequente.

Diante disso, o papel do professor é fundamental para que o desenvolvimento dessas novas formações aconteça, pois não se formam espontaneamente. A atividade de estudo precisa ser dirigida pelo professor, que, a partir de uma estruturação de sua disciplina escolar, dará sentido ao aprendizado da criança, para que supere os conhecimentos espontâneos e avance no desenvolvimento do pensamento por conceitos. Segundo Nepómniaschaya (1979) são os processos de ensino e educação que vão modificando substancialmente esse desenvolvimento. De acordo com Davidov (1979), a atividade de estudo é a atividade guia no desenvolvimento psicológico do escolar. 
Nepómniaschaya (1979) assevera que a complexificação dos conteúdos das disciplinas influencia significativamente no desenvolvimento psíquico do escolar. $\mathrm{O}$ autor alega que ao introduzirem recursos especiais na explicação dos conteúdos, os alunos mais novos têm condições de efetuar as atividades ofertadas a alunos mais velhos, pois o recurso possibilita a assimilação do conhecimento científico do material didático oferecido. Nesse sentido, Nepómniaschaya (1979, p. 27) afirma que "o domínio dos conhecimentos científicos é condicionante de uma reestruturação cardenal no desenvolvimento do pensamento da criança".

Cada ciência possui uma complexidade de operações, tarefas e objetos para compreendê-la. A partir desse conhecimento, a criança vai conseguindo resolver as atividades e ampliando a possibilidade de resolver outras tarefas mais complexas, principalmente quando o procedimento para resolvê-las apresenta um caráter generalizador, que a ajudará a solucionar diversos problemas matemáticos, por exemplo. Por isso, conhecer as operações matemáticas de soma, subtração, divisão e multiplicação não são suficientes para a resolução de uma tarefa, mas faz-se necessário conhecer as estruturas complexas que envolvem uma operação matemática, como, por exemplo, as relações de igualdade/desigualdade, parte/todo (NEPÓMNIASCHAYA, 1979)

A apresentação de conceitos abstratos precisa se correlacionar com o conhecimento concreto, para ampliar a capacidade da criança em diferentes disciplinas escolares, pois um conteúdo da Matemática, se generalizado, auxiliará na compreensão das outras ciências. De acordo com Nepómniaschaya (1979, p.29), “[...] o desenvolvimento das ações generalizadas (comparação, análise, síntese, etc) define o êxito com que se aplicam os procedimentos assimilados".

Não é qualquer atividade que pode transformar o sujeito. A definição de atividade apresentada por Leontiev (2014a, p. 68), refere-se aos “[...] processos psicologicamente caracterizados por aquilo a que o processo, como um todo, se dirige (seu objeto), coincidindo sempre com o objetivo que estimula o sujeito a executar esta atividade, isto é, o motivo". Dessa forma, segundo Tuleski e Eidt (2016), o que o indivíduo faz, para se configurar em uma atividade, precisa ter uma necessidade e, por isso, de um objeto que a satisfaça.

O motivo de uma atividade está relacionado às condições concretas e à consciência das novas relações que esta atividade exige dela, como é o caso da atividade de estudo. $\mathrm{O}$ fato de a criança estar na escola não é suficiente para que entenda a importância do estudo. É um ponto de partida, mas precisa estar consciente do lugar que ocupa. Por esse motivo, a escola precisa ir oferecendo isso a ela, por meio de atividades produtivas que vão fazendo-a superar o lúdico, como informa Mukhina (1996).

O estudante precisa então ser provocado, para que desenvolva a atividade de estudo, que possibilitará a complexificação dessa interfuncionalidade dos processos psicológicos superiores. As atividades realizadas nos processos de avaliação e intervenção com estudantes que apresentam as queixas escolares, necessitam considerar e contribuir para o desenvolvimento dessas funções, conforme veremos no próximo item.

\section{A avaliação e o grupo de apoio psicoeducacional: o estudo de caso do André}

A pesquisa foi realizada em um município do interior do Paraná, com crianças da primeira fase do ensino fundamental que apresentavam dificuldades no processo de escolarização, principalmente no que tange à Matemática, à escrita e à leitura. O objetivo dessa pesquisa consistiu em elaborar procedimentos de avaliação das queixas escolares, utilizando subsídios da Psicologia Histórico-Cultural em parceria com estudiosos do México, que analisam o processo de avaliação neuropsicológica. 
O estudo foi desenvolvido em duas fases. Na primeira foi realizada a avaliação psicológica de oito alunos, por psicólogos participantes da pesquisa, acadêmicos da graduação do curso de Psicologia da Universidade Estadual de Maringá (UEM) e discentes de pós-graduação, em nível de mestrado e doutorado, do Programa de Pós-Graduação da Universidade Estadual de Maringá.

A partir dessa avaliação, considerando a necessidade das crianças de obterem um acompanhamento para o enfrentamento das dificuldades presentes no processo ensinoaprendizagem, foi desenvolvida a segunda fase, por meio da efetivação do grupo de apoio psicoeducacional, no segundo semestre de 2018 , com cinco crianças ${ }^{1}$.

Essa atividade foi realizada por duas psicólogas, uma cursando mestrado em Psicologia e outra realizando estágio pós-doutoral no Programa de Pós-Graduação citado anteriormente. Dentre os cinco alunos que participaram do grupo, escolhemos para este artigo fazer referência a uma criança, que terá André como nome fictício. André estava frequentando a terceira série do ensino fundamental e tinha oito anos.

\section{A avaliação psicológica}

Para realizar as avaliações psicológicas $\underline{\underline{2}}$, primeiro nos encontramos com as orientadoras pedagógicas da escola participante da pesquisa, para sabermos quais crianças avaliaríamos. Nesse momento, foi-nos apresentada a queixa de André, de 7 anos, que cursava o $3^{\circ}$ ano: aluno com TDAH, epilepsia, suspeita de autismo, não alfabetizado e com dificuldade de socialização.

As etapas da avaliação foram as seguintes: encontro com a família, encontro com a professora, cinco encontros com a criança e encontros finais com todos os envolvidos. Nos primeiros encontros a mãe e a professora assinaram o Termo de Consentimento Livre e Esclarecido (TCLE), aceitando participar da pesquisa. No primeiro encontro com a criança, André assinou o Termo de Assentimento Livre e Esclarecido (TALE), que foi lido e explicado para ele.

Durante todo o processo, realizamos encontros semanais com a equipe de pesquisa, planejando o encontro seguinte e discutindo o caso das crianças. A análise explicativa do desenvolvimento da criança foi entregue em forma de relatório e discutida com todos os envolvidos, cada um de uma forma: a criança, a família e a escola. Todos os encontros foram realizados em dupla, em uma sala, no interior da biblioteca da escola que a criança estudava e eram gravados e relatados em um diário de campo.

Nos encontros estruturamos atividades para analisar o desenvolvimento da criança de acordo com a Psicologia Histórico-Cultural. Buscamos, no encontro com a mãe, entender a história da construção da queixa escolar, suas potencialidades e as relações estabelecidas entre a criança e os membros familiares, para compreensão dessas questões no contexto societário. Era uma criança que fazia uso de medicamentos, como Metilfenidato, porém teve convulsões que a fizeram parar o uso. De forma geral, a mãe comentou que André tinha uma fala infantilizada, que era uma criança "complicada", no sentido de não conseguir estabelecer acordos com ele, que possuía dificuldade com leitura e escrita, mas que se esforçava para aprender, principalmente com a ajuda do irmão mais velho.

A professora estava acompanhando-o fazia apenas dez dias, e informou-nos que era uma criança que tinha muitas dificuldades e necessitava de mediações constantes, porém que às vezes "paralisava". Em outras palavras, se recusava a fazer as atividades propostas. Percebemos essa recusa em nossos encontros, principalmente no início do processo

\footnotetext{
1 A pesquisa foi aprovada pelo comitê de ética de uma universidade do Paraná sob o processo número CAAE 70843717.1.0000.0104, parecer n. 2.451.326.

2 As etapas do processo de avaliação psicológica foram explicadas na tese de doutorado de Vieira (2020).
} 
avaliativo. Ele se mostrava quieto e não fazia contato visual, porém, com o decorrer das atividades, construímos um vínculo e já se mostrava mais disposto a realizar atividades referentes a brincadeiras. Reputamos que seja oportuno ressaltar que a brincadeira é uma atividade importante para o desenvolvimento das funções psicológicas superiores e que gesta a próxima atividade: de estudo (VYGOTSKI, 1936/1997).

Nesse sentido, foi possível analisar o desenvolvimento das funções psicológicas superiores a partir de brincadeiras que preparamos para André. Uma dessas foi a de faz de conta com o tema fazenda, que apresentamos alguns objetos para a criança simbolizar. André escolheu alguns blocos, afirmando que seriam as árvores da fazenda, mas esses objetos não mantiveram esse significado para ele no decorrer da brincadeira, mostrando uma dificuldade em usar signos e necessitando de objetos concretos para brincar.

Em outras atividades percebemos o quanto a criança precisava da ajuda do adulto para resolver as tarefas. Em outras palavras, alguns processos se encontravam em sua zona de desenvolvimento próximo, logo, se fossem compartilhados com os adultos e houvesse as mediações necessárias, seriam internalizados pela criança. Por exemplo, em uma atividade de formar conjuntos e sequência de objetos deveria sugerir um nome para o grupo apresentado. Ele nomeava o grupo com ajuda, a partir da função dos objetos, usando verbos e não palavras que agrupavam os elementos: "para fazer comida", "que anda". No decorrer da atividade fez algumas generalizações mais complexas, como "comida" e "formas de sapato", mostrando a importância do outro no desenvolvimento de sua forma de pensamento.

Em outros vários momentos André mostrou a importância do outro na organização de seu pensamento, como, por exemplo, para montar um quebra-cabeças. Inicialmente, o aluno apresentou dificuldades (quis montar em cima da mesa e não conseguia organizar as peças no espaço dela), mas, com dicas sobre as imagens das peças e a organização do todo, conseguiu montá-lo, mostrando dificuldades em antecipar sozinho a finalidade de ação relacionada à internalização do objeto, mas com ajuda conseguiu planejar e organizar seu comportamento.

Esse resultado se confirmou em demais atividades que visavam avaliar outras funções psicológicas, como a atenção e a memória. A atividade preparada para avaliar a atenção voluntária consistiu em um jogo de perguntas e repostas em que André não podia falar certas cores ou repetir cores em suas respostas. Eram oferecidos cartões coloridos para ajudá-lo a seguir as regras do jogo. Ele fez uso dos cartões para realizar a tarefa, o que significa que a partir de um recurso mediador conseguia controlar sua atenção.

$\mathrm{Na}$ atividade que avaliava a memória, André tinha que repetir uma lista de palavras. Ele recordou três palavras e analisamos que repetia cada palavra após escutá-la, mostrando que essa era uma estratégia que utilizava para memorizá-la. $\mathrm{Na}$ segunda parte dessa atividade foi analisado o domínio do uso funcional de um signo para fins de memorização, utilizando cartões para auxiliar nesse processo. André não conseguiu se lembrar de todas as palavras e necessitou de ajuda para lembrar as relações que havia feito, das figuras com as palavras. Após a ajuda conseguiu recordar 5 palavras. Isso aponta para o fato de que precisa da orientação do adulto para internalizar ações e dominar o uso funcional de algum signo para fins de memorização.

O uso de signos são fundamentais para o desenvolvimento das funções psicológicas superiores, como mencionamos anteriormente. Durante todo o processo avaliativo observamos que André conseguia utilizar recursos mediadores, mas precisava de ajuda para tal, mostrando que vários processos psíquicos ainda são compartilhados com os adultos, ou seja, não foram internalizados. André também necessitava de ajuda para começar a fazer a atividade, no sentido de incentivá-lo e animá-lo a participar. De modo geral, constatamos que as dificuldades apresentadas na queixa escolar se encontravam no nível pedagógico, precisando de ajuda para superá-las no processo de escolarização. Importante ressaltarmos 
que, para que haja superações, a estrutura da inteligência depende das questões de afeto e pedagógicas. Portanto, a partir da organização de comportamento que o adulto lhe proporcionava ele conseguia realizar generalizações, classificações, planejar, escrever e resolver operações matemáticas.

Consideramos que o psicólogo poderia auxiliar André na superação de suas dificuldades, por meio de grupo de apoio psicoeducacional. Assim, após avaliação, o aluno passou a frequentar esse grupo.

\section{O grupo de apoio psicoeducacional}

Nesse item explicaremos como as atividades com os mediadores externos e os signos, a partir da intervenção das profissionais, auxiliavam a criança no processo de superação das formas imediatas de relação com o mundo para avançar na complexificação das funções psicológicas superiores.

As atividades foram organizadas intercalando as lúdicas com as orientadas (de estudo), com mediações (intervenções) pelas psicólogas. Foram realizados 15 encontros, mas vamos focar a apresentação do primeiro, do terceiro, do quarto e do quinto encontro. Nessa sequência não selecionamos o segundo encontro, pois André não estava naquele dia.

Como não é possível trabalhar com todos os encontros, selecionamos esses quatro (primeiro, terceiro, quarto e quinto), que mostram as transformações psíquicas entre as funções psicológicas superiores, pois esse aluno vem de um processo avaliativo, como consta cima, que, diferentemente das avaliações tradicionais, na perspectiva da Psicologia Histórico-Cultural, busca desenvolver as funções psicológicas superiores. Dessa forma, o trabalho interventivo continuou nesse processo, agora com intervenções mais pontuais.

A queixa apresentada pela escola, com relação a André, referia-se à dificuldade com a leitura, a escrita e os cálculos matemáticos. $\mathrm{Na}$ avaliação inicial foi percebido que sua memória, atenção, percepção e organização espaço-temporal estavam muito ligadas à situação concreta, por isso necessitavam da mediação dos adultos com certa frequência, para organizar seu comportamento e dar início às atividades, conforme apresentamos no item anterior.

Como temos visto na literatura que se apoia na Psicologia Histórico-Cultural, o ambiente escolar e, mais especificamente, o ensino e a educação são fundamentais para o desenvolvimento das funções psicológicas superiores, porque permitem ao indivíduo sair de uma inteligência prática e avançar para a construção da inteligência mediada, que faz uso dos instrumentos psicológicos (signos).

Segundo Vygotski (1991, p. 32), a unidade dialética entre inteligência prática e uso dos signos é o que "[...] constitui a verdadeira essência no comportamento complexo [...]", dando origem à atividade simbólica, que é uma atividade organizadora. Nesse sentido, nosso trabalho com o grupo de apoio psicoeducacional foi desenvolver atividades que, na apresentação dos signos, auxiliasse as crianças a superarem a forma elementar das funções, para a internalização dos signos, a fim de desenvolver as funções psíquicas superiores. A fala irá o tempo todo permear as instruções das atividades junto com o uso dos instrumentos, como figuras, mapas, material dourado para os cálculos, a própria escrita e os rabiscos, entre outros utilizados à medida que as atividades foram aplicadas.

Vygotski (2000) afirma que a fala e o uso dos instrumentos incorporados à ação dão origem às formas humanas da inteligência prática e abstrata, que aos poucos se complexificam, à medida que situações desafiadoras vão sendo colocadas e exigidas da criança uma reorganização da sua forma de lidar com ela. É nesse processo, de resolver o problema, que as formas espontâneas não dão conta e requerem o uso de instrumentos (mediadores auxiliares) que vão reorganizar as funções psíquicas, transformando-as em funções intrapsíquicas. 
Algumas vezes percebemos uma fala infantilizada de André, que pode ser uma forma de a criança obter atenção e ser tratada de forma diferenciada, mas influencia no seu processo de aprendizado, porque a limitação do vocabulário infantil afeta a percepção, a memória e a atenção, que acabam se deslocando para a situação imediata, o concreto. Por isso, quando vimos que André utilizava, inicialmente, a fala verbalizada, egocêntrica, para resolver as provas de controle sobre memorização, observamos que existia um esforço ativo para organizar formas de solucionar o problema apresentado, que aos poucos ia cedendo espaço para a fala interiorizada. Ele então utilizava a fala como um instrumento para a solução de um problema e deixava de apelar para o adulto e recorrer à fala internalizada, que é falar para si mesmo ao invés de recorrer ao adulto (VYGOTSKI, 1991).

Percebemos que nas atividades propostas o aluno utilizava a fala para preceder a ação, e pensava sua ação, não a realizava de forma espontânea. Vygotski (1991, p. 38) afirma que quando isso acontece "[...] a fala dirige, determina e domina o curso da ação, surge a função planejadora da fala, além da função, já existente da linguagem, de refletir o mundo exterior".

No primeiro encontro com o grupo, as atividades propostas foram a apresentação pessoal, com destaque para às matérias escolares que as crianças mais gostavam. Também foram realizadas a elaboração das regras de convivência, os relatos sobre a importância da escola e a confecção do calendário. Como mediadores utilizamos várias figuras que representassem comportamentos diversificados em sala de aula, para auxiliarem na confecção das regas no cartaz, e a utilização da escrita como forma de fixação do conteúdo das regras.

Percebemos que as figuras auxiliaram as crianças na elaboração das regras, pois direcionaram a sua atenção para a atividade proposta. Por exemplo: as crianças que escreveram as regras (02 alunas) conseguiram focar mais a atenção e dispersaram menos. Além disso, depois da elaboração das regras, a lembrança delas funcionava como um meio de controle do comportamento para algumas crianças, não sendo apenas uma exigência externa, mas um estímulo interno, que regulava o comportamento. Nos encontros subsequentes as crianças voluntariamente relembravam as regras, o que auxiliava na concretização das atividades, direcionando sua atenção.

Como defendemos que as funções psicológicas não se desenvolvem isoladamente, as figuras foram importantes para as crianças recordarem as palavras que seriam utilizadas na elaboração das regras, trabalhando assim a memória lógica e a atenção, bem como sua relação com a linguagem. Esta foi um signo mediador na orientação da memória e da atenção, ou seja, percebemos a inter-relação entre essas funções por meio da utilização das figuras para recordarem de palavras que seriam utilizadas na elaboração das regras. Nesse encontro, no momento de estabelecimento das regras de convivência com o grupo, André não se prontificou a fazer o registro no cartaz, mas fez importantes contribuições com ideias a respeito de quais as regras deveriam ser implantadas.

Nesse dia, alguns livros na estante chamaram a sua atenção, e ele foi vê-los. Como estávamos desenvolvendo a atividade, foi necessário chamá-lo para retornar, e ele o fez. $\mathrm{Na}$ conversa inicial do grupo, em que as psicólogas perguntaram sobre o que significava escola para eles, André disse que escola era "nada", mas, ao se deslocar até os livros, deixou em evidência que há algum sentido que ultrapassa a sua definição de escola como "nada". Tal sentido é reforçado por sua resposta de que a escola é importante para aprender.

No trabalho com a Matemática, realizado no terceiro encontro, iniciamos com a história de sua constituição na humanidade, mostrando, por meio de recursos visuais, como os homens primitivos, os egípcios e atualmente o cálculo está na vida das pessoas. Os instrumentos que utilizamos foram as figuras para a contação de história, as pedras grandes, 
a régua graduada, a trena, a fita métrica, o metro para carpinteiro, o mapa mundi, o globo terrestre, o papel e o lápis grafite.

Foi um encontro introdutório sobre a Matemática, e à medida que contávamos a história apresentávamos aos alunos uma diversidade de objetos para ajudá-los a lembrar dos fatos. Explicamos o surgimento da unidade, da dezena, da centena e solicitamos que os alunos representassem alguns números, que forma escritos do quadro, com o material dourado. As figuras também foram utilizadas como recursos auxiliares, para que na atividade da semana seguinte fossem mediadoras na efetivação da memória lógica das crianças, ajudando-as a recordarem a história contada, além de focarem a atenção.

Segundo Mukhina (1996, p. 59), “[...] a atividade lúdica facilita o desenvolvimento da atenção voluntária e da memória voluntária". Novamente a linguagem falada permeia a atividade, auxiliando, por meio das palavras, a conceituação dos objetos e na "[...] construção da imagem do objeto como ideia [...]” (MARTINS, 2011, p. 192).

Tal atividade lúdica foi registrada em forma de história em quadrinhos no quarto encontro. Retomamos o conteúdo com as crianças, lembrando-as das formas de medidas, dos objetos e quem foram os primeiros a introduzirem o conceito de número. Além disso, figuras foram utilizadas como recurso auxiliar para poderem colocar na sequência em que a história havia acontecido. Recordamos com as crianças o que seria uma história em quadrinhos e como devia ser organizada. Colocamos gibis, livros, revistas à disposição delas e, a partir das figuras que encontrassem, deveriam contar a história.

Nesse encontro os alunos utilizaram a memória para retomar a história que tinha sido contada no encontro anterior. Novamente temos a mediação da linguagem falada, que, por meio da palavra, reorganiza as diversas funções psicológicas superiores, ampliando a possibilidade de generalizações e abstrações, diferenciando cada vez mais o pensamento escolar da criança pré-escolar.

As palavras, que durante a apresentação da história foram apresentadas para nominar os objetos (fita métrica, trena, mapa mundi, entre outros), juntamente com a apresentação desses, complexificam a forma de pensar da criança e ajudam-na a lembrar. No caso desse encontro, do conteúdo sobre a história da Matemática. Dessa forma, a criança é capaz de selecionar seu foco de interesse (atenção), para cumprir com a montagem da história. Foi o que aconteceu no grupo. Memória e atenção, nesse movimento sistêmico, influenciam o pensamento que se organiza para elaborar uma história em quadrinhos.

As crianças ainda tinham nas figuras os sinais que auxiliaram na sequência da história da Matemática, mas primeiro utilizamos a linguagem oral, por meio de perguntas, para despertar a lembrança do que havia sido trabalhado no encontro anterior e direcionar a atenção para o que proporíamos como atividade: a construção de uma história em quadrinhos. Todas participaram, inclusive André.

Significa que a proposição de uma lembrança por meio de figuras altera as funções do pensamento, porque a criança não recorre à memória natural para lembrar da história, mas sua memória estabelece conexões com outras funções, para se tornar uma memória lógica. Segundo Vygotski (1999), a memória lógica surge da relação entre memória e pensamento.

Nesse dia André estava distraído, pois se interessou por um gibi. Na elaboração da história em quadrinhos queria ler a história do gibi e não conseguia iniciar a atividade proposta. Percebendo seu interesse pela leitura do material, à medida que folheava, foram sendo realizadas perguntas dos personagens e como poderiam se encaixar na história da Matemática.

$\mathrm{Na}$ atividade, André escreveu corretamente a maioria das palavras e foi capaz de perceber quando uma letra ou uma palavra faltava na frase que elaborou. Conseguiu estabelecer uma sequência na história, mas a falta de foco na atividade fez com que tivesse 
alguns erros ortográficos, e não avançou muito na história. Mesmo não concluindo, com a mediação das pesquisadoras conseguiu iniciar e escreveu.

No quinto encontro trabalhamos a classificação dos números, enfatizando os naturais, os conceitos de par, ímpar, unidade, dezena, dúzia, centena e milhar. Utilizamos, como estímulos auxiliares, as figuras de diversos objetos, para as crianças agruparem e darem nomes aos grupos. Também foram usados blocos lógicos, para brincarem de um tipo de dominó em que o jogador escolhe uma peça que se assemelhe com algum dos atributos da peça anterior, e assim sucessivamente. Além disso, retomamos a história da Matemática e fizemos relação com a história da classificação dos números.

Foram propostos três jogos, sendo dois com o objetivo de trabalhar com a classificação e um de iniciar as operações com números. No primeiro, as crianças foram divididas em dois grupos (meninas $\mathrm{x}$ meninos), para os quais foi apresentado um grande número (15-20) de cartões com figuras de diversos objetos e proposto que dividissem os cartões agrupando os objetos pertencentes à mesma categoria. As meninas montaram cinco grupos e os meninos montaram quatro. André estabeleceu dois grupos: um que nomeou de "os alimentos" e o outro de "material". Demonstrou facilidade com os conceitos que compreendem generalizações e ajudou o colega do seu grupo. $\mathrm{Na}$ sequência, cada criança escreveu no papel sulfite o nome dos grupos que nomeou e a quantidade de cartões que os compuseram.

No segundo momento foi proposto que as crianças jogassem o dominó com blocos lógicos juntamente com as psicólogas. As 28 peças dos blocos foram divididas igualmente, entre as crianças e as psicólogas, não sobrou peças. A ordem em que as crianças jogaram foi proposta pelas psicólogas. Em seguida, a criança que iniciou o jogo escolheu uma peça, colocou sobre a mesa e falou sobre as características da peça escolhida. O participante seguinte jogou uma peça que se assemelhava com alguma das características da peça anterior e assim sucessivamente. André conseguiu verificar a semelhança da sua peça com a que estava sobre a mesa e concluiu a atividade.

Após a realização dos dois primeiros jogos foi retomada a história da Matemática e conversamos sobre a história da classificação dos números. Destacamos a classificação dos números naturais e enfatizamos os conceitos de unidade, dezena, centena, dúzia, milhar, par e ímpar. Percebemos, nessas atividades de classificação, que André já conseguia operar com a palavra, como constituinte da linguagem, em uma de suas funções complexas, que é a generalização. Primeiro estabeleceu, por meio das figuras, categorias que as uniam em grupo, e, depois, com os blocos lógicos, conseguiu estabelecer relações entre os diferentes blocos (tamanho, cor, espessura, modelo geométrico). Segundo Luria (1994), quando se domina a palavra é porque já se domina um complexo sistema de relações e associações sobre um dado objeto.

Conseguir perceber o objeto e estabelecer uma constância na relação entre eles é entender a utilização à percepção humana e de sua capacidade ortoscópica, que é ver o objeto corretamente, quer dizer que seu tamanho, forma e cor permanecem, como afirma Vygotski (1993). Essa constância não depende das situações causais, do ângulo, e não está presente desde o início da vida, mas deve ser considerada como um produto do desenvolvimento histórico. De acordo com o autor, a mudança da percepção, de instável para adquirir essa estabilidade, no que se diz respeito às sensações de proximidade e distância, começa a se ver na relação dessa função com o sistema das outras funções.

Nessa primeira atividade, as figuras, como recursos auxiliares externos da memória, foram importantes para ajudar as crianças a trabalharem com a classificação de grupos e elaborarem conceitos generalizados. As funções, como percepção, atenção e sensação, estavam sendo movimentadas pela necessidade imposta da atividade, em reconhecer os objetos (percepção), aplicar sentido a eles (sensação) e selecionar o que estava vendo (atenção). 
A dificuldade de algumas crianças em classificar não é porque têm algum problema no desenvolvimento das funções, mas o que percebemos é que desconhecem alguns objetos representados nas figuras. No entanto, fica clara a transição da memória involuntária para a memória lógica, pois utilizam os meios auxiliares e usam a escrita como sistema simbólico para registrar o que experenciaram.

A figura funcionou como um instrumento mnemotécnico e auxiliou a criança na próxima atividade, quando foram introduzidos os blocos lógicos, pois foi requerido que saísse da situação concreta (figura) e abstraísse as características do objeto, ainda que apresentado na forma concreta. Isso é importante, pois, segundo Vygotski e Luria (1996), a memória de objetos visuais no pré-escolar vai sendo substituída no escolar pela memória verbal. Por consequência, a fala e as formas lógicas é que "[...] começam a desempenhar o papel de ferramentas decisivas para a rememoração" (VYGOTSKI; LURIA,1996, p. 213),

Várias outras atividades foram aplicadas nas crianças (15 encontros), mas elucidamos essas quatro, objetivando mostrar que o trabalho com atividades que potencializem o movimento interfuncional entre as funções implica em oferecer estímulos novos às crianças, para auxiliarem e funcionarem como meios de internalização das funções psicológicas superiores.

Dessa forma, percebemos que as intervenções no grupo ajudaram André a organizar seu pensamento sem necessitar constantemente da mediação das psicólogas. Logo após a instrução de uma atividade, ele engajou-se em seu desenvolvimento. Além disso, utilizou mais ativamente os recursos auxiliares para sua memorização, ou seja, os objetos, como material dourado, blocos lógicos, instrumentos de medição, figuras e anotações gráficas, foram funcionalmente auxiliares no desenvolvimento de sua memória cultural e não apenas objetos sem sentido.

Em relação à linguagem escrita, trabalhamos no grupo com registros na maioria dos encontros, para que entendesse que a atividade proposta estava diretamente ligada à atividade de estudo, em que a escrita é fundamental. André não apresentou nenhuma resistência em escrever e mostrou ver sentido na escrita. Quando não tinha certeza de como escrevia uma palavra pedia auxílio para as psicólogas e, com a mediação, conseguia fazer. Também observamos que já está lendo em letra caixa alta, letra impressa e letra cursiva, diferentemente de outra criança do grupo, que apresenta limitação, pois lê somente no formato de letra em caixa alta.

Durante o grupo interventivo, nas atividades voltadas para a Matemática, verificamos que André compreendeu as noções de medida, conjunto, classificação, quantidade e número. $\mathrm{Na}$ subtração e na soma conseguiu fazer as contas mentalmente, mas na divisão ainda recorreu ao papel, utilizando figuras de bola e riscos como recursos, não precisando mais do desenho ou da presença concreta do objeto.

Por isso, resgatar a importância dos signos é fazer com que o indivíduo deixe de ter conexão direta com a realidade e estabeleça novas conexões. Nesse sentido, todas as funções mediadas pelos signos apresentam mudanças não em sua estrutura externa, mas em suas relações entre as funções, o que leva às relações interfuncionais.

Os avanços que percebemos em André são perceptíveis em seu relacionamento com as outras crianças do grupo - não deixando de se posicionar, de expressar o que estava sentindo. Já conseguia utilizar os signos como instrumentos de memorização de palavras e números, o que levou a muitas participações nos encontros, porque não tinha medo de errar e estava mais interessado em aprender as palavras e os números.

\section{Algumas considerações}

Podemos concluir que as funções psicológicas superiores se formam na interação social homem-natureza, a partir da mediação do outro, que vai inserindo os instrumentos 
psicológicos (signos) e dando significado às relações. Tais relações, que se encontravam no nível das inter-relações, vão se convertendo em funções psicológicas, pois são internalizadas pelo homem tornando-se intrapsicológicas. As funções psicológicas antes naturais passam a ser culturais, ou seja, as estruturas psicológicas primitivas, biológicas, se reorganizam em estruturas psicológicas superiores, o que acontece a partir das combinações e nexos entre as funções.

Como vimos na literatura apresentada, o desenvolvimento das funções psíquicas superiores começa primeiro com a ação imediata das funções psíquicas, por meio de formas diretas de adaptação, e depois o comportamento se complexifica a partir "[...] das mudanças dos meios empregados para a tarefa [...]" (VYGOTSKI; LURIA, 2007).

Nesse sentido, como partimos da premissa de que as funções atuam dentro de um sistema interfuncional, estabelecendo novas relações e conexões, à medida que a criança interage com os signos há uma reorganização das funções, como de atenção, de memória, de abstração. A criança vai elaborando formas menos diretas para resolver os desafios escolares, fortalecendo o uso das funções psicológicas superiores, tão importantes para a atividade de estudo. Quer dizer que memória, atenção voluntária, percepção, emoção, formação de conceitos, pensamento e imaginação relacionam-se entre si, em forma de nexos diferentes a cada etapa do desenvolvimento. Esse processo não tem relação direta com a idade, mas com as exigências postas na relação do sujeito com esse meio.

Nosso trabalho não objetiva tomar o lugar do professor, mas acreditamos que a intervenção psicológica com crianças com dificuldades no processo de escolarização precisa atuar em conjunto com esse profissional, pois é o professor quem ensinará as crianças os conhecimentos científicos tão importantes para o desenvolvimento da atividade de estudo.

\section{Referências}

ALMEIDA, Sandro Henrique Vieira de, \& ANTUNES, Mitsuko Aparecida Makino. Teoria vigotskiana sobre memória: possíveis implicações para a educação. ANPED 28 REUNIÃO ANUAL, 2005, Caxambú, Anais Eletrônicos..., Caxambu. MG, 2005. Disponivel em: http://28reuniao.anped.org.br/gt20.htm. Acesso em: ago. 2019.

ASBAHR, Flávia da Silva Ferreira, \& NASCIMENTO, Carolina Picchetti. Criança não é manga, não amadurece: conceito de maturação na teoria histórico-cultural. Psicologia:

Ciência e Profissão, v. 33, n.2, p.414-427, 2013. Disponível em: https://www.scielo.br/scielo.php?pid=S14148932013000200012\&script=sci_abstract\&tln $\mathrm{g}=$ pt. Acesso em: mar. 2020.

ANTUNES, Mitsuko Aparecida Makino . A Psicologia no Brasil: leitura histórica sobre a sua constituição. São Paulo:Unimarco; Editora EDUC, 1998.

ELKONIN, Daniil. B. (1987). Sobre el problema de la periodización del desarrollo psíquico en la infancia. In Davidov, Vasili Vasilievich \& Shuare, Marta (Org..), La psicología evolutiva y pedagógica en la URSS: Antología (pp.104-124). Moscou: Ed. Progreso, 1987,p. 104-124.

GEORG, Ivone. Buscando sentidos: presença e movimento do conceito de signo em alguns textos de Vygotski. 2002, 89f. (Dissertação de mestrado). - Programa de Pósgraduação em Psicologia, Universidade Federal de Santa Catarina, Santa Catarian, 2002. Disponível em: https://repositorio.ufsc.br/bitstream/handle/123456789/83326/301945.pdf?sequence=1 \&isAllowed $=\mathrm{y})$. Acesso em: mar. 2019. 
LEONTIEV, Alexis Nikolaevich. O desenvolvimento do psiquismo. Lisboa: Livros Horizonte, 1978.

LEONTIEV, Alexis Nikolaevich. El desarrollo psíquico del niño en la edad preescolar. In V. In DAVIDOV, Vasili Vasilievich \& SHUARE, Marta (Org..), La psicología evolutiva y pedagógica en la URSS: Antología. Moscou: Editorial Progreso, 1987, p. 57-70.

LEONTIEV, Alexis Nikdaevich. Uma contribuição à teoria do desenvolvimento da psique infantil. In VIGOTSKII, Lev Semionovitch; LURIA, Alexander Romanovich \&

LEONTIEV, Alexis Nikdaevich. Linguagem, desenvolvimento e aprendizagem. 13. ed. São Paulo: Ícone editora, 2014a. p.59-84.

LEONTIEV, Alexis Nikdaevich. Os princípios psicológicos da brincadeira pré-escolar. In VIGOTSKII, Lev Semionovitch; LURIA, Alexander Romanovich \& LEONTIEV, Alexis Nikdaevich. Linguagem, desenvolvimento e aprendizagem. 13. ed. São Paulo: Ícone editora, 2014b. p.119-142.

MARTINS, Ligia Márcia. O desenvolvimento do psiquismo e a educação escolar: contribuições à luz da psicologia histórico-cultural e da pedagogia histórico-crítica. 2011, 250f. Tese (Livre docência em Psicologia). Universidade Estadual Paulista Júlio de Mesquita Filho, São Paulo, 2011. Acessível em: https://formacaodocente.files.wordpress.com/2012/09/martins_ligia__o_desenvolvimento_do_psiquismo_e_a_educacao_escolar.pdf. Acesso em: ago. 2019.

MASSIMI, Marina. História da Psicologia Brasileira: da época colonial até 1934. São Paulo: EPU, 1990.

MUKHINA, Valéria. Psicologia da idade pré-escolar. Trad. De Claudia Berline. São Paulo: Martins Fontes, 1996.

NEPÓMNIASCHAYA, N.I. Desarrollo psiquico y enseñanza. In: Petrovski, A. Psicologia evolutiva y pedagogica. Moscou: Progresso, 1979, p. 23-43.

PASQUALINI, Juliana Campregher. Contribuições da psicologia histórico-cultural para a educação escolar da criança de $\mathbf{0}$ a $\mathbf{6}$ anos: desenvolvimento e ensino em Vigotski, Leontiev e Elkonin. 2006, 207f. Dissertação de Mestrado. Faculdade de Ciências e Letras, Universidade Estadual Paulista (UNESP), campus Araraquara, 2006.

PASQUALINI, Juliana Campregher, \& EIDT, Nádia Maria. Periodização do desenvolvimento infantil e ações educativas. In: Pasqualini, Juliana Campregher, \& Tsuhako, Yaeko Nakadakari. Proposta pedagógica para a Educação Infantil do Sistema Municipal de Ensino de Bauru/SP. 1. ed. Bauru:, v. 1, 2016, p. 101-148. Disponível em:

https://www2.bauru.sp.gov.br/arquivos/arquivos_site/sec_educacao/proposta_pedagogic a_educacao_infantil.pdf. Acesso em: mar..2019.

TULESKI, Silvana Calvo; EIDT, Nádia Maria. A periodização do desenvolvimento psíquico: atividade dominante e a formação das funções psicológicas superiores. In: MARTINS, Ligia Martins; ABRANTES, Angelo Antônio; FACCI, Marilda Gonçalves Dias. Periodização histórico-cultural do desenvolvimento psíquico: do nascimento à velhice. Campinas, SP: Autores Associados, 2016, p.35-61.

VIEIRA, Ana Paula A. A avaliação psicológica de crianças que enfrentam dificuldades no processo de escolarização como instrumento de intervenção: proposta a partir da psicologia histórico-cultural 2020, 400 fls. Tese (Doutorado em Educação). Universidade Estadual de Maringá, Maringá, Paraná, 2020. 
VYGOTSKY, Lev Semionovitch. A formação social da mente. São Paulo: Martins Fontes, 1991.

VYGOTSKI, Lev Semionovitch. Obras Escogidas IV: problemas de la psicologia infantil. Madrid: Visor, 1996.

VYGOTSKI, L. S. Diagnóstico del desarrollo y clínica paidológica de la infancia difícil. In L. S. Vygotski, Obras Escogidas. Tomo 5. Madrid: Visor y Ministerio de Educación y Ciencia. (Trabalho original publicado em 1936), 1997, p. 275-338.

VYGOTSKY, Lev Semionovitch. Sobre os sistemas psicológicos. In L. S. Vigotski. Teoria e método em Psicologia. São Paulo: Martins Fontes, 1999, p.103-135.

VYGOTSKI, Lev Semionovitch. Obras Escogidas III: problemas del desarrollo de la psique. Madrid: Visor, 2000.

VYGOTSKI, Lev Semionovitch. A construção da linguagem e pensamento. São Paulo: Martins Fontes, 2001.

VYGOTSKI, Lev Semionovitch. Aprendizagem e desenvolvimento intelectual na idade escolar. In: Leontiev, A. N., et al. Psicologia e Pedagogia: bases psicológicas da aprendizagem e do desenvolvimento. São Paulo: Centauro, 2005, p.25-42.

VYGOTSKY, Lev Semionovitch; LURIA, Alexander Romanovich. Estudos sobre a história do comportamento: Estudos sobre a história do comportamento símios, homem primitivo e criança. Porto Alegre: Artes Médicas, 1996.

VYGOTSKI, Lev Semionovitch; LURIA, Alexander Romanovich. El instrumento y el signo em el desarrollo del niño. Madrid: Fundación Infancia y Aprendizaje, 2007. 